therefore we shall never have been in receipt of this pay, which we were led to suppose we should receive within a few months of our landing in India.

Bengal, June, 1883. I am, Sir, yours obediently,

\section{"DIGITAL DILATATION OF CONTRACTED PYLORUS."}

To the Editor of THE LANCET.

SIR,-Having read with pleasure in THE LANCET of June 16 th of the two patients operated upon by Prof. Loreta by forcible finger dilatation of the pylorus, I thought it might be agreeable to you to learn that they are continuing to do well. The vomiting they had been troubled with tor years has not recurred; and from having been in a starving condition they have returned to full bealth and strength.

A third case was afterwards operated on, Prof. Loreta's diagnosis having been "simple stenosis of pylorus." The patient died in thirty-six hours, from causes entirely independent of the operation. The autopsy showed the incision in the stomach perfectly closed, gas and liquid light, and pylorus well dilated.

The week before last, Prof. Loreta operated on a woman, the diagnosis being "stenosis of cardiac orifice," with entire success, and the patient continues improving. As the operator could not reach to dilate with his fingers, he was obliged to resort to an instrument. The fifth and last operation took place on July 15th. The diagnosis, "stenosis of pylorus," was also in this case justified by the state of things found on operating. The success was perfect, as in the other cases. This last patient, too, continues improving, and everything justifies the expectation of a favourable result. The digital dilatation of the two orifices of the stomach, but especially of the pylorus, first conceived and executed by our illustrious surgeon, and named accordingly "Loreta's operation," is destined to enjoy a brilliant future in the surgical world. Since its adoption, attention has been directed to the existence, little before suspected, of the frequency of pyloric narrowing; and the surprising results obtained fully justify the most sanguine expectations.

Prof. Loreta lays special stress on dilating with the fingers rather than with instruments, as be is thus enabled to carry the dilatation to the utmost possible extent short of rupturing the parts, for the fingers can feel how far we can safely go, which no instrument can of course do. The dilatation by the fingers once effected, we may reasonably count on its permanence, judging from the before-mentioned instances, the first of which was operated on in September, 1882. The suture for the wound in the stomach adopted by Professor Loreta is that of Apolito Gély, made with a single needle. This snture is quickly made and perfectly secure.

I send the report made to the Bologna Benedettina Academy by Professor Loreta, in which he minutely describes his manner of operating, and the exact rules of differential diagnosis of simple narrowing of the pylorus. It would be very gratifying if this succinet account of Loreta's operation should find room in the columns of your world-renowned journal. I am, Sir, your obedient servant, Guido Pedrazzoli, M.D.

Clinical Hospital, Bologna, Italy, July 21st, 1883.

\section{SCOTTISH NOTES.}

\section{(From our own Correspondent.)}

MANY friends of Dr. Paterson (Bridge of Allan) will join in expressing sincere sympathy with that gentleman in the trial he has endured recently in the loss of no fewer than three of his sons. All of these young men have died in different parts of the world ; the last in South Africa, where he served as captain in the Mounted Volunteers. Another was a medical man.

\section{ABERDEEN ROYAL INFIRMARY.}

A special meeting of the managers of this institution has been held to consider whether the position held by Dr. Robertson as euperintendent should be again held by a medical man or made open to all applicants. It was generally felt that the position should be held by a medical man, and that such applicants should have a preference, but that the eituation should be advertised as open to all. The salary is $£ 250$ a year, with free house, $\& c$. In all the other chief hospitals throughout Scotland, certainly in all to which a large medical school is attached, this office is held by medical men; and it would seem a retrograde step to introduce a change in a system which everywhere works so well.

SALICYLATE OF SODA AS A POISON.

Some months ago a case was mentioned in this column in which death was alleged to have occurred after the use of fifteen grains of salicylate of soda, and it was then deemed worthy of further inquiry. It appears now that the widow of the deceased has raised an action against the chemist at Aberdeen who supplied the drug for $£ 750$ damages, and the case has been sent for proof. It is alleged that the drug was a poisonous compound other than that ordered. In connexion with the case a discussion took place before the sheriff last week regarding the possession of the powders. The woman bought six of these, of which one was used by the deceased, another given to Dr. Robertson who attended the case, and the remaining four to Dr. Frank Ogston for the purpose of analysis or experiment. Pursuer's agent now complains that Dr. Ogston, without his permission or that of the Procurator Fiscal, had given one of these powders to the defendant, and that this was a plain breach of duty on the part of Dr. Ogston. The sheriff, however, refused a motion to have this powder restored to pursuer. The case excites considerable medical interest, and will be tried during this month.

\section{COMBE AND GILCHRIST LECTURES.}

The courses of these lectures, which have been arranged for the ensuing winter and spring, are as follows :-The Combe Lectures on "Physiology and Health" will bedelivered, as usual, by Dr. Andrew Wilson, in Burnt Island, Dalkeith, Audrie, Alloa, and Leith. Dr. Wilson will also deliver a special course, arranged for by Mr. James Coates, jun., at Paisley, and another in Perth, on "Health." Galashiels, Hawick, Peebles, Selkirk, and Jedburgh will each be favoured with three lectures on "Electricity and its Modern Applications," by Mr. W. L. Carpenter, under the auspices of the Gilchrist Trust; and the same towns will also be visited by Dr. Wilson, who will lecture on "The Beginnings of Life."

\section{SCOTTISH METEOROLOGICAL SOCIETY.}

A very important meeting of this Society was held last week. It was stated that $£ 4400$ of the $£ 5000$ needed to equip the Ben Nevis Observatory was already subseribed, and that there is now no doubt of the work being carried on under the most favourable circumstances. Mr. John Murray announced, on the part of the Fisheries' Committee, that it was determined to continue river observations as beretofore; that a few naturalists should be asked to make special observations at several of our chief fishing stations and lochs; and that the recommendation in favour of a zoological station should be adopted, and Granton Quarry, on the Forth, be utilised for the purpose. The quarry has an area of about ten acres, and depths varying to sixty feet; this it is proposed to enclose and stock with all kinds of fish and marine invertebrates. A barge fitted specially for work here will be moored in the enclosure, a launch provided for dredging purposes, and a naturalist appointed to the station. A library, instruments, \&c., will be amply provided, besides accommodation for other naturalists who may wish to work at the station. From various sources funds have been obtained to carry out this ambitious scheme, and work will be commenced forthwith. Mr. Murray undertakes to supply instruments and books, and seems to have inspired others with his own enthusiasm in the matter. The Society may be most heartily congratulated on such a report of good work done as that mentioned at this meeting.

\section{BELFAST.}

(From our Correspondent.)

QUEEN'S COLLEGE, BELFAST.

The President of Queen's College, Belfast, has just written, for private circulation, a paper of great interest, entitled "University Education in Ireland; the Royal University and the Queen's Colleges." In this pamphlet, the appearance of which has aroused considerable attention, Dr. 